\title{
In-situ контроль температуры поверхности ГЭС КРТ в процессе роста методом низкотемпературной поляризационной пирометрии
}

\author{
С.А. Дулин, С.В. Рыхлицкий, Е.К. Иванов, Н.И. Назаров, Н.Н. Михайлов, С.А. Дворецкий, \\ М.В. Якушев \\ Институт физики полупроводников им. А.В. Ржанова СО РАН, \\ Новосибирск, 630090, пр.Ак. Лаврентьева 13 \\ тел: (383) 330 -8716,, факс (383) 333-2771, эл. почта: dulin@isp.nsc.ru
}

DOI 10.34077/RCSP2019-103

Представлены усовершенствованный метод низкотемпературной поляризационной пирометрии и его аппаратно-программная реализация для in-situ бесконтактного измерения температуры поверхности ГЭС КРТ в процессе молекулярной эпитаксии.

Большинство технологических ростовых камер МЛЭ снабжены специальными оптическими окнами для визуального и эллипсометрического контроля поверхности роста.

Эти окна, после некоторой модернизации, могут быть использованы и для задач in-situ низкотемпературной пирометрии (измерения температуры) растущего слоя ГЭС КРТ. В работе обсуждаются проблемы, связанные с практическим применением метода низкотемпературной поляризационной пирометрии в камере МЛЭ и пути их преодоления [1]. В частности, при многократных циклах роста происходит запыление поверхности рабочего окна и, как следствие, уменьшение оптического пропускания измерительного тракта. Для отслеживания этого процесса и своевременной корректировки показаний, в прибор введен дополнительный двухспектральный фотометрический канал.

Выбранные поддиапазоны дополнительного канала (1.9 2.0 мкм. и $2.4 \div 2.5$ мкм.) на определенной стадии эпитаксиального роста, когда структура становится непрозрачной, позволяют использовать их для пирометрического определения температуры.

Таким образом, обеспечивается дополнительный контроль показаний основного канала и внесение поправок, связанных с возможными помехами от низкотемпературных источников.

$\mathrm{B}$ рабочем диапазоне удалось достичь линейную зависимость фотометрического сигнала от температуры, что позволяет проводить калибровку пирометра непосредственно на рабочей камере. Приведены измерительная схема и краткое техническое описание разработанного низкотемпературного пирометра, а также методика и результаты экспериментальных измерений.

\section{Лuтература}

[1] С.А. Дворецкий, С.А. Дулин, Н.Н. Михайлов, С.В. Рыхлицкий, Ю.Г. Сидоров. Способ бесконтактного измерения температуры. Патент РФ № 2149366, Бюл. № 14 от 20.05.2000г. 